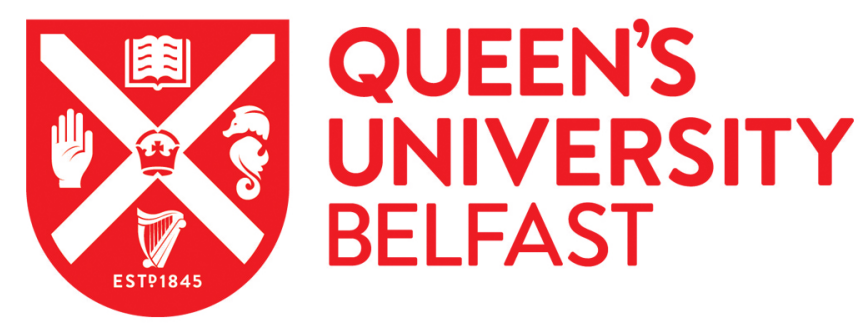

\title{
Parched plants: survival and viability of invasive aquatic macrophytes following exposure to various desiccation regimes
}

Coughlan, N. E., Cuthbert, R. N., Kelly, T. C., \& Jansen, M. A. K. (2018). Parched plants: survival and viability of invasive aquatic macrophytes following exposure to various desiccation regimes. Aquatic Botany, 150, 9-15. https://doi.org/10.1016/j.aquabot.2018.06.001

Published in:

Aquatic Botany

Document Version:

Peer reviewed version

Queen's University Belfast - Research Portal:

Link to publication record in Queen's University Belfast Research Portal

Publisher rights

Copyright 2018 Elsevier.

This manuscript is distributed under a Creative Commons Attribution-NonCommercial-NoDerivs License

(https://creativecommons.org/licenses/by-nc-nd/4.0/), which permits distribution and reproduction for non-commercial purposes, provided the author and source are cited.

\section{General rights}

Copyright for the publications made accessible via the Queen's University Belfast Research Portal is retained by the author(s) and / or other copyright owners and it is a condition of accessing these publications that users recognise and abide by the legal requirements associated with these rights.

Take down policy

The Research Portal is Queen's institutional repository that provides access to Queen's research output. Every effort has been made to ensure that content in the Research Portal does not infringe any person's rights, or applicable UK laws. If you discover content in the Research Portal that you believe breaches copyright or violates any law, please contact openaccess@qub.ac.uk. 


\section{Accepted Manuscript}

Title: Parched plants: survival and viability of invasive aquatic macrophytes following exposure to various desiccation regimes

Authors: Neil E. Coughlan, Ross N. Cuthbert, Thomas C. Kelly, Marcel A.K. Jansen

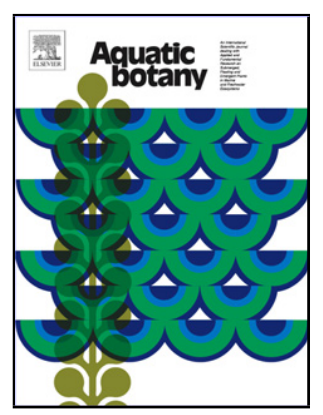

PII: S0304-3770(18)30043-3

DOI: https://doi.org/10.1016/j.aquabot.2018.06.001

Reference: AQBOT 3038

To appear in:

Aquatic Botany

Received date:

$19-2-2018$

Revised date:

$15-6-2018$

Accepted date:

$18-6-2018$

Please cite this article as: Coughlan NE, Cuthbert RN, Kelly TC, Jansen MAK, Parched plants: survival and viability of invasive aquatic macrophytes following exposure to various desiccation regimes, Aquatic Botany (2018), https://doi.org/10.1016/j.aquabot.2018.06.001

This is a PDF file of an unedited manuscript that has been accepted for publication. As a service to our customers we are providing this early version of the manuscript. The manuscript will undergo copyediting, typesetting, and review of the resulting proof before it is published in its final form. Please note that during the production process errors may be discovered which could affect the content, and all legal disclaimers that apply to the journal pertain. 
Parched plants: survival and viability of invasive aquatic macrophytes following exposure to various desiccation regimes

Neil E. Coughlan ${ }^{1,2 *}$, Ross N. Cuthbert ${ }^{2}$, Thomas C. Kelly ${ }^{1} \&$ Marcel A.K. Jansen ${ }^{1}$

${ }^{1}$ School of Biological, Earth and Environmental Sciences \& Environmental Research Institute, University College Cork, Distillery Field, North Mall, Cork, Ireland.

${ }^{2}$ Institute for Global Food Security, School of Biological Sciences, Medical Biology Centre, Queen's University Belfast, Belfast BT9 7BL, Northern Ireland

*Correspondence: neil.coughlan.zoology@gmail.com

\section{Highlights}

- Increased vapour-pressure deficit significantly reduced survival of aquatic plants.

- Elevated temperature reduced regeneration capacity even at higher relative humidity.

- Mortality rates increased under longer desiccation exposure across all treatments.

- Overall, longer exposure times also resulted in reduced regeneration capacity.

- Floating species displayed a greater regeneration capacity than submerged macrophytes.

Abstract 
Invasive alien species represent a serious worldwide threat to natural and semi-natural ecosystems. Although successful overland transport of invasive aquatic macrophytes can be facilitated by more mobile organisms or anthropogenic activity, tolerance to desiccation is likely a limiting factor. Particularly in the case of vegetative fragmentary propagules. Here we examined survival and subsequent viability (i.e. regeneration by production of new shoot or root growth) for whole plantlets of two floating (Azolla filiculoides, Lemna minuta) and stem fragments of three submerged (Elodea canadensis. E. nuttallii, Lagarosiphon major) invasive macrophytes following exposure to different desiccation regimes. Species were exposed to selected temperature $\left(20,27,36{ }^{\circ} \mathrm{C}\right)$ and relative humidity $(18,38,60,85 \% \mathrm{RH})$ combinations for up to six hours. In general, floating plants displayed greater survival and viability than submerged species. Overall, survival and viability decreased significantly for all species with increased desiccation exposure times. In essence, increased vapourpressure deficit significantly reduced survival of aquatic plants. Although reduced humidity rates particularly decreased survival and viability, increased temperatures were observed to bolster the impact of certain humidity treatments. In particular, when exposed to low $\mathrm{RH}(\leq 38 \% \mathrm{RH})$, little or no viability was observed after $2 \mathrm{~h}$. Contrastingly, propagules kept under $\mathrm{RH}$ above $60 \% \mathrm{RH}$ at $20{ }^{\circ} \mathrm{C}$ retained viability for considerably longer intervals above $4-6 \mathrm{~h}$. Overall, desiccation as a biosecurity tool alone is likely inadequate to prevent the spread of fragmentary propagule stages, as even small desiccated fragments that appear to be dry may still be viable.

Key words: aquatic invasive species, biosecurity, desiccation-tolerance, invasive plants, invasive species management, spread prevention, vapour-pressure deficit.

\section{Introduction}

Globally, aquatic invasive species (AIS) are a major driver of detrimental change to freshwater ecosystems (Sala et al. 2000; Simberloff et al. 2013; Havel et al. 2015; Piria et al. 2017). In particular, 
invasive aquatic plants such as invasive macrophytes, can negatively alter freshwater community dynamics and ecosystem function, often via the establishment of abundant populations that threaten native biodiversity through a variety of physical, chemical and biological impacts (Schultz and Dibble 2012; Kuehne et al. 2016; Lu et al. 2018; O'Hare et al. 2018). For example, replacement of native plant species by invasive macrophytes can lead to reduced invertebrate and fish diversity, and water quality deterioration (Schultz and Dibble 2012; Lu et al. 2018). Management options for eradication and control of established invader populations are often complex, resource-intensive and costly endeavours (Hussner et al. 2017; Piria et al. 2017; Coughlan et al. 2018). Accordingly, biosecurity protocols that prevent further AIS spread have become an integral aspect of invasive species management (Simberloff et al. 2013; Caffrey et al. 2016; Cuthbert et al. 2018), and often represent the most cost effective management option (Hussner et al. 2017).

While vectors that underpin the natural dispersal of AIS are frequently unknown (Coughlan et al. 2017c), freshwater systems are highly vulnerable to accidental or deliberate AIS introductions due to their exposure to multiple transport pathways (Dudgeon et al. 2006; Banha and Anastácio 2015; Banha et al. 2016). Despite a restricted ability to self-disperse, an abundance of AIS have successfully managed to rapidly colonise and recolonise hydrological unconnected sites (e.g. ponds and lakes; De Meester et al. 2002; Santamaría 2002; Hussner 2012; Coughlan et al. 2017b). Therefore, it has often been concluded that various means of assisted dispersal must be readily available to facilitate species spread and biological invasion (Santamaría 2002; Jerde et al. 2012; Barnes et al. 2013; Bruckerhoff et al. 2015; Green 2016). In particular, successful overland dispersal of AIS can be enabled by more mobile organisms (zoochory) such as birds (Green 2016; Coughlan et al. 2017a), and anthropogenic activity such as angling and boating (Johnson et al. 2001; Rothlisberger et al. 2010).

Tolerance to desiccation is a limiting factor in the overland dispersal of many AIS, particularly invasive macrophytes (Evans et al. 2011; Barnes et al. 2013; Bickel et al. 2015). Accordingly, various stakeholder groups actively promote best practice biosecurity protocols (e.g. 'Check, Clean, Dry') which incorporate desiccation as a tool to reduce invader spread (Anderson et al. 2014). Moreover, desiccation also represents a critical challenge to the survival of established aquatic plants during 
periods of water loss, such as seasonal drought or other periods of water drawdowns (Barrat-Segretain and Cellot 2007; Barnes et al. 2013). Accordingly, quantifying survival and subsequent viability (i.e. regeneration by production of new shoot or root growth within a specified time period) of invasive macrophyte vegetative propagules following desiccation can contribute to predicting dispersal ability, enhance biosecurity protocols with extended drying times, improve AIS eradication and control techniques, and inform correct disposal of weeds following removal from infested sites or contaminated equipment (Barnes et al. 2013; Bruckerhoff et al. 2015; Hussner et al. 2017).

Many invasive aquatic macrophytes predominantly reproduce and spread by vegetative propagation, particularly via vegetative fragments (Umetsu et al. 2012; Li et al. 2015; Redekop et al. 2016). Plant fragmentation within aquatic environments is considered to occur through either selfinduced autofragmentation or allofragmentation, i.e. fragmentation as a result of disturbance, such as changes in water velocity, sediment mobility, and animal or anthropogenic activity (Riis et al. 2009; Heidbüchel et al. 2016). In particular, foraging herbivores are thought to facilitate fragmentary propagule creation and dispersal (Bakker et al. 2016). Although fragments are predominately spread within the aquatic medium by water currents (hydrochory), desiccation tolerances of vegetative fragments are key to understanding their overland dispersal. Yet, surprisingly, little information exists within the literature on how desiccation influences survival and viability of aquatic plant fragments (Evans et al. 2011). Although previous studies have attempted to quantify desiccation tolerance for some invasive macrophytes, most studies have simply analysed desiccation under ambient laboratory or field conditions, while a few have replicated average expected field conditions for a given time of year (see Jerde et al. 2012; Barnes et al. 2013; Bruckerhoff et al. 2015). However, zoochorous and anthropogenic vectors can provide climatic envelopes that are distinct from the ambient, which may either enhance or decrease the dispersal potential of aquatic plant propagules by provision of differential desiccation regimes (temperature and humidity; Jerde et al. 2012; Coughlan et al. 2015a), which can be expressed in relation vapour-pressure deficit (VPD), i.e. the difference between the actual moisture content and the total saturation point for air at a given temperature. 
In this study, we determined the survivability and subsequent viability of five invasive aquatic macrophytes exposed to differential desiccation regimes of selected temperature $\left(20,27\right.$ and $\left.36{ }^{\circ} \mathrm{C}\right)$ and relative humidity $(18,38,60$ and $85 \% \mathrm{RH})$ combinations, for up to $6 \mathrm{~h}$. Two species with floating and three species with fully submersed lifecycles were selected. All selected species can reproduce via relatively small vegetative fragments, such as one frond, or a single node stem fragment (see Heidbüchel et al. 2016). We hypothesise that floating, rather than submerged, species will better tolerate desiccation regimes for longer exposure times (as these species are, at least in part, naturally exposed to the air). Similarly, we hypothesised that cooler air temperature and higher air moisture content (i.e. high RH; low VDP values) will promote greater propagule survivability and subsequent viability.

\section{Methods}

\section{Cultivation of study organisms}

A stock of Azolla filiculoides Lamarck, was cultivated in non-aerated aquaria on half-strength Hutner's growth media, a prepared culture media for provision of nutrients for optimal growth (Brain and Solomon 2007). Equally, non-axenic cultures of Lemna minuta Kunth, were maintained on halfstrength Hutner's growth media in $100 \mathrm{ml}$ magenta vessels within the laboratory under a natural daylight and ambient temperature regime (Lahive et al. 2011). Stocks of Elodea canadensis Michx., E. nuttallii (Planchon) H. St. John, and Lagarosiphon major (Ridley) Moss, were separately maintained in aerated aquaria filled with pond water and containing soil substrate both obtained from the research ponds and gardens adjacent to the School of Biological, Earth and Environmental Sciences, University College Cork, Ireland. All species displayed excellent survival and sustained growth over a three month cultivation period. All species were collected locally during spring and summer months from different sites throughout County Cork, Ireland. All waste invasive plant material was destroyed by autoclaving. 


\section{Desiccation Protocol}

To better asses varying environmental scenarios, desiccation regimes consisted of various selected temperature $\left(20,27,36^{\circ} \mathrm{C}\right)$ and humidity $(18,38,60,85 \% \mathrm{RH})$ combinations (Table 1$)$. Temperatures were chosen to reflect typical ambient summer conditions across temperate latitudes $\left(20-27^{\circ} \mathrm{C}\right.$; e.g. Jerde et al. 2012), when decontamination of equipment by drying may be attempted (Anderson et al. 2014). In addition, the reported temperature range of known zoochorous microclimate envelopes (21 $-33{ }^{\circ} \mathrm{C}$; Coughlan et al. 2015a) are considered. A broad range of relative humidity condition were examined to assess disparity of VPD across selected temperatures. Replication of treatments varied with species: floating species $n=9$, submerged species $n=18$ ). A chick brooder (Brinsea TLC-40 Advance Brooder) was used to provide a climatically controlled chamber. Conditions were monitored and recorded in real-time using a MSR data-logger with a dual temperature $\left( \pm 0.5^{\circ} \mathrm{C}\right)$ and humidity $( \pm 2 \% \mathrm{RH})$ sensor (MSR145B4A, FT/020, FH/020, FP/020; $\mathrm{MSR}^{\circledR}$ data-loggers and measuring instruments). The specified temperatures and humidity combinations remained stable throughout the experiments, excepting $85 \% \mathrm{RH}$ at $36{ }^{\circ} \mathrm{C}$ which was excluded from his study. Silica gel beads were used to reduce humidity to low levels as required. Desired conditions of temperature and humidity were pre-set and established before plants were placed in the chamber. Independent desiccation trials were run for each species at all temperature and humidity combinations. At each sampling time point, propagules (or propagule groups) were selected and returned to the growth medium in separate magentas. All control samples were directly transferred between magenta vessels, without exposure to drought. Control $n=9$ and 18 for floating and submerged species, respectively. Following a set time period for recovery and resumption of growth, propagules were assessed for survival (presence or absence of new shoot or root growth) and viability (i.e. generation of biomass over a specific period of time). The standard conditions for plant growth were $16 \mathrm{~h}$ light and $8 \mathrm{~h}$ darkness at a light intensity of $50 \mu \mathrm{mol} \cdot \mathrm{m}^{-2} \cdot \mathrm{s}^{-1}$ (cool white fluorescent lamps) and a temperature of $22 \pm 2{ }^{\circ} \mathrm{C}$.

Preparation and desiccation sampling 
Fresh summer growth of $A$. filiculoides was harvested from the aquaria and excess media gently removed using filtration paper. Damp plantlets were weighed and those ranging between $200-270$ mg were selected and briefly returned to growth media (circa 30 mins) before experimental commencement. All plantlets were then removed from the media and gently dried using filtration paper. Damp plantlets were individually placed on inverted petri-dishes. All petri-dishes were simultaneously placed within the climate chamber to undergo desiccation. Samples were returned to fresh growth medium $(150 \mathrm{ml})$ at regular intervals for up to $4 \mathrm{~h}$ to quantify desiccation survivability and viability. Plantlets which displayed a resumption of growth after drought stress were considered to have survived, and viability was measured as biomass after ten days, under standard growth conditions.

Lemna minuta colonies were extracted from the magenta vessels and excess media was gently removed using filtration paper. Damp colonies were then spread out on inverted plastic petri-dishes. The petri-dishes were simultaneously loaded with $L$. minuta and placed within the experimental chamber. Samples (i.e. propagule groups, each comprised of four colonies of three fronds) were returned to fresh growth medium $(100 \mathrm{ml})$ after having been kept for up to $6 \mathrm{~h}$ within the climate chamber. Plantlets which displayed a resumption of growth after drought stress were considered to have survived, and viability was measured as biomass after seven days, under standard growth conditions.

Fragments of E. canadensis, E. nuttallii and L. major, were harvested from mature plants. Fragments were cut from the top sections of unbranched stems, and apical buds were excluded. Selected fragment length (mean $\pm \mathrm{SE}$ ) was based on the number of nodes (E. canadensis: $56.8 \pm 1.1$ mm, $n=10$ nodes; E. nuttallii: $43.5 \pm 1.2 \mathrm{~mm}, n=8$ nodes) or the number of whorls (L. major: $23.1 \pm$ $0.3 \mathrm{~mm}, n=5$ whorls). Fragments were cut immediately above the final node/whorl at the upper end and immediately below that of the lower. In previous experiments, $\geq 70 \%$ survival was observed at these node and whorl counts (Reidy et al. unpublished). Fragments were harvested as required and briefly maintained in pond water filled aquaria prior to experimental use (c. 30 mins). Plant fragments were then randomly selected from the aquaria, excess media was gently removed using filtration paper, 
and fragment length and weight was recorded. Damp plant fragments were re-weighed and placed in groups of three (one fragment of each species) on inverted plastic petri-dishes within the experimental chamber. Samples were returned to pond water $(200 \mathrm{ml}$; sterilised by autoclave in advance) at regular intervals for up to $4 \mathrm{~h}$ to quantify desiccation survivability and viability. Resumption of growth after drought stress was assessed by the presence of new growth and/or roots after 28 days, under standard growth conditions. Propagules which displayed new shoot and/or root growth were considered to have survived, while the biomass of new shoot growth was used as a measure of viability. New growth was removed from the old and weighed separately.

\section{Statistical analysis}

Statistical analyses were performed using R v3.4.4. (R Core Development Team 2018). The effect of vapour-pressure deficit (VPD) on overall plant survivability was analysed using a generalised linear model (GLM) assuming a binomial error distribution across the ubiquitous $1 \mathrm{~h}$ and $2 \mathrm{~h}$ exposure treatments. A binary classification was used to differentiate between floating and submerged species. Then, survivability of floating (A. filiculoides and L. minuta) and submerged (E. canadensis, E. nuttallii and L. major) experimental plant groups was analysed separately across their analogous exposure treatments (up to $4 \mathrm{~h}$ ). Azolla filiculoides and L. minuta were additionally assessed individually as survivability and viability were considered following different exposure times (up to 6 h). Here, the effects of desiccation treatment, exposure time and species on overall survivability within plant groups were assessed individually using separate GLMs. The generation of new biomass in plant groups was analysed non-parametrically using proportional odds logistic regression, again in respect to the desiccation treatment, exposure time and species effects. Explanatory terms of non-significance were eliminated from all models to achieve parsimony. We employed Tukey's contrast post hoc tests to generate multiple comparisons where an explanatory variable yielded significance at the $95 \%$ confidence level. 


\section{Results}

\section{Vapour-pressure deficit (VPD) related mortality}

Increasing VPD (see Table 1) significantly reduced the survivability of aquatic plants during desiccation treatments $\left(\chi^{2}=80.24, d f=1, P<0.001\right)$, and survivability was significantly lower under longer exposure times $\left(\chi^{2}=64.88, d f=1, P<0.001\right)$. Further, there was a significant 'VPD $\times$ exposure' interaction $\left(\chi^{2}=17.86, d f=1, P<0.001\right)$, reflecting greater VPD-related mortality under longer exposure times. Floating rather than submerged species better survived all desiccation regimes at the ubiquitous $1 \mathrm{hr}$ and $2 \mathrm{hr}$ exposure treatments $\left(\chi^{2}=519.58, d f=1, P<0.001\right)$. Moreover, the effect of increasing VPD appears to be driven by RH rather than temperature under the current experimental parameters.

\section{Survival and viability of Azolla filiculoides and Lemna minuta}

Azolla filiculoides and L. minuta displayed limited survivability under low RH conditions, and desiccation impact tended to increase with temperature (Fig. 1). Desiccation treatments significantly reduced the overall survivability of $A$. filiculoides $\left(\chi^{2}=129.46, d f=11, P<0.001\right)$ and L. minuta $\left(\chi^{2}\right.$ $=155.50, d f=11, P<0.001)$ and mortality rates increased under longer desiccation exposure times for both species (A. filiculoides, $\chi^{2}=153.55, d f=1, P<0.001 ;$ L. minuta, $\chi^{2}=135.51, d f=1, P<$ $0.001)$.

Overall, treatment significantly affected viability, i.e. generation of biomass, in both $A$. filiculoides $\left(\chi^{2}=237.74, d f=11, P<0.001\right)$ and L. minuta $\left(\chi^{2}=287.27, d f=11, P<0.001\right)$, and biomass generation was significantly reduced under longer desiccation exposure times for both species (A. filiculoides, $\chi^{2}=120.85, d f=1, P<0.001 ;$. minuta, $\chi^{2}=92.42, d f=1, P<0.001$ ). Desiccation treatments under $18 \% \mathrm{RH}, 38 \% \mathrm{RH}$ and $60 \% \mathrm{RH}$ reduced A. filiculoides biomass generation significantly when compared to control groups irrespective of temperature regime (all $P<0.01$ ), whilst only L. minuta exposed to $18 \%$ RH was significantly different to controls across all temperatures (all $P<0.01)$. Temperature increases from $20^{\circ} \mathrm{C}$ to $36^{\circ} \mathrm{C}$ significantly reduced growth of treated $A$. 
filiculoides at $38 \% \mathrm{RH}(P=0.04)$, however, there was no statistically significant effect at other humidity levels across corresponding temperatures (all $P>0.05$ ). Contrastingly, for L. minuta, temperature increases from $20^{\circ} \mathrm{C}$ to $36^{\circ} \mathrm{C}$ significantly reduced growth at $60 \% \mathrm{RH}(P<0.001)$ alone. Overall, both species retained some viability after $1 \mathrm{~h}$ exposure even at low humidity of $18 \% \mathrm{RH}$ across all temperatures, but in most instances displayed little or no survival after $2 \mathrm{~h}$ of exposure under lower RH levels (Fig. 1). At $60 \%$ RH, A. filiculoides and L. minuta retained viability for over $2 \mathrm{~h}$ and between 4 - $5 \mathrm{~h}$, respectively, for all tested temperatures. At $85 \% \mathrm{RH}$, increased temperatures tended to reduce viability of A. filiculoides to a greater extent than L. minuta. In general, L. minuta displayed greater levels of viability than A. filiculoides across the majority of experimental desiccation regimes (Fig. 1).

Survival and viability of Elodea canadensis, E. nuttallii and Lagarosiphon major

Survival of E. canadensis and E. nuttallii was minimal across all desiccation treatments. Survivability of L. major was similarly greatly reduced under longer exposure times and lower humidity levels. Yet, L. major demonstrated relatively high survivability through regeneration of both shoots and roots under shorter exposure times and higher humidity levels (Table S1). Across all species, survivability demonstrated via shoot regrowth was generally more pronounced than root regrowth alone. Overall, however, humidity and temperature treatments significantly reduced the survivability of E. canadensis, E. nuttallii and L. major $\left(\chi^{2}=199.14, d f=11, P<0.001\right)$ and mortality increased under longer desiccation exposure times $\left(\chi^{2}=47.50, d f=1, P<0.001\right)$. Survivability was significantly different between the three submerged species $\left(\chi^{2}=92.41, d f=2, P<0.001\right)$, reflecting greater survivability of L. major compared to both Elodea species (all $P<0.001$ ). However, this effect was dependent on the desiccation treatment given the 'treatment $\times$ species' interaction yielded significance $\left(\chi^{2}=42.39, d f=\right.$ 22, $P=0.006$ ), wherein particularly high survivability was recorded for L. major at higher humidity levels relative to the other species. Yet, this effect was nullified under lower humidity levels and longer exposure times (Table S1). 
Biomass generation of submerged spp. was significantly affected by desiccation treatment $\left(\chi^{2}=\right.$ 198.11, $d f=11, P<0.001)$ and was reduced significantly under increasing desiccation exposure times $\left(\chi^{2}=49.49, d f=1, P<0.001\right)$. Overall, exposure to $18 \% \mathrm{RH}, 38 \% \mathrm{RH}$ and $60 \% \mathrm{RH}$ significantly reduced biomass generation irrespective of temperature regime when compared to control groups (all $P<0.001)$. Although biomass generation was substantially reduced overall at $85 \% \mathrm{RH}$ treatments relative to control groups across all examined temperatures $\left(20^{\circ} \mathrm{C}\right.$ and $\left.27^{\circ} \mathrm{C}\right)$ these effects were not found to be significant at either temperature (all $P>0.05$ ). Generally, a decrease biomass production under desiccation at low humidity treatments was substantial and sustained regardless of temperature (all $P<0.001$ ). However, for L. major, the $60 \% \mathrm{RH}$ treatment tended to anomalously drive greater biomass generation under increasing temperatures (Fig. 2). Biomass generation was also significantly different between species $\left(\chi^{2}=97.39, d f=2, P<0.001\right)$, with $L$. major generating significantly more biomass overall than both Elodea species following desiccation treatments (all $P<0.001$ ). However, a significant 'treatment $\times$ species' interaction $\left(\chi^{2}=40.90, d f=22, P=0.009\right)$ indicated that such species-level effects were treatment-dependent, reflecting far greater biomass generation by L. major at higher RH levels relative to other species (Fig. 2). Indeed, at $85 \% \mathrm{RH}$ L. major retained viability for $4 \mathrm{~h}$ post-removal from the aquatic medium. Overall, although E. canadensis and E. nuttallii plantlets exhibited particularly low viability across $\mathrm{RH}$ and temperature regimes, substantial mortality was observed for all three species under longer desiccation exposure times and lower RH treatments (Fig. 2).

\section{Discussion}

\section{Differential desiccation resistance between floating and submerged species}

As predicted, floating, rather than submerged, species better tolerated desiccation regimes for longer exposure times. Overall, survival and viability, i.e. regeneration by production of new shoot or root growth within a specific time, decreased significantly for all species with increased time spent outside 
the aquatic medium. Similarly, propagules kept under lower VPD displayed greater survivability. Although the effects of reduced humidity were particularly profound in decreasing survival and viability, increased temperatures and longer exposures were observed to bolster the impact of some humidity treatments. This was especially the case for floating species, which displayed relatively higher survivability and viability under lower temperature treatments. Submerged species, particularly Elodea spp., displayed marked reductions in survival and viability, with little or no biomass regeneration observed at short exposure times irrespective of temperature treatment. In general, sustained viability post desiccation was most frequently indicated by new shoot growth alone, followed by combined shoot and root growth. Little overall root growth may reflect the lack of sediment within the magenta vessels. Accordingly, enhance fragmentary survival could possibly occur in the presence nutrient-rich sediment (Li et al. 2015).

The data here present clear, species-specific desiccation tolerances for the examined invasive aquatic macrophytes at the specified conditions and exposure times. Better tolerance of desiccation exposure by floating aquatic plantlets likely reflects the use of whole plants rather than fragmented sections. Accordingly, neither L. minuta nor A. filiculoides were subjected to the added stress of fragmentation. The mechanical stress of stem fragmentation may have contributed to the reduced desiccation resistance displayed by the examined submerged species. Equally, the cuticle layer of submerged aquatic macrophytes may simply be minimised or lacking (Mommer and Visser, 2005), making these plants more susceptible to desiccation. Thus, a more substantial cuticle layer will likely aid the desiccation resistance of floating and emergent species, and therefore overland dispersal.

The present study also excluded apical tips for submerged, but not for floating, species. Vegetative reproduction of $A$. filiculoides and L. minuta occurs within meristematic tissue located at the centre of plantlet and base of fronds. Submerged fragments with apical tips generally have greater colonization and regeneration abilities, and higher growth rates than fragments without apical tips (Riis et al. 2009; Umetsu et al. 2012). Therefore, it is reasonable to assume that fragmentary propagules of submerged species with an apical tip would likely retain greater post desiccation viability than those without. In addition, larger fragments generally have greater colonization and regeneration abilities 
than smaller ones, due to their higher energy reserves and photosynthetic rates (Riis et al. 2009; Kuntz et al. 2014; Li et al. 2015). In an examination of E. nuttallii fragment survival that included the apical tip, Hoffmann et al. (2015) observed the percentage mortality of fragments to decrease with a higher numbers of initial nodes. However, even relatively small vegetative fragments, such as one frond, or a single node stem fragment can retain substantial regeneration capacities (Kuntz et al. 2014; Heidbüchel et al. 2016). Therefore, while larger fragments and greater node counts will likely retain a greater capacity for survival, the influence of fragment size on plant dispersal and colonization ability requires confirmation (Kuntz et al. 2014; Hoffmann et al. 2015; Redekop et al. 2016). Moreover, large clumps of plant material, such as stems coiled into several layers, can display increased resistant to desiccation. This greater tolerance to desiccation follows general physical principles, as larger clumps should have a lower surface area to volume ratio than single stems, and thus lower evaporative loss (Bruckerhoff et al. 2015).

Cooler temperature and higher air moisture content will promote survivability and viability. Unsurprisingly, lower temperatures and higher relative humidity (i.e. low VPD values) improved overall desiccation resistance. Under these conditions water loss rates are reduced as the air becomes more saturated. Accordingly, cooler damp conditions will likely promote invader spread. Although known microclimatic regimes of zoochorous vectors will vary, propagules entangled within the plumage of mallard ducks (Anas platyrhynchos) can experience conditions between $21-33{ }^{\circ} \mathrm{C}$ and 58 $-72 \%$ RH depending on the anatomical area (Coughlan et al. 2015a). Therefore assisted overland dispersal by waterbirds can provide for suitable conditions for the retention of substantial viability. Although daily movements by mallards between sites are often relatively short $(3-5 \mathrm{~km})$, some ducks have been recorded to regularly travel in excess of $20 \mathrm{~km}$ (Bengtsson et al. 2014). Moreover, at flight speeds of $65 \mathrm{~km} \mathrm{~h}^{-1}$, mallards can complete a long-distance dispersal movement within a two hour period (Coughlan et al. 2015b).

Microclimatic regimes associated with anthropogenic transport of fragmentary propagules will likely vary quite markedly. Plant fragmentary propagule stages adhering to the external surfaces of 
vectors such as vehicles, trailers and watercraft will likely experience more dramatic and less favourable conditions due to direct air and environmental exposure. However, propagules contained within equipment items such as kayaks, bait buckets, keep net bags, and propeller flag-bags, are likely to experience distinct microclimatic regimes of lower VDP rates. Although anthropogenic vectors can display a substantial disparity in frequency of differential river catchment visitation, some watersport enthusiasts are known to visits multiple different sites, often several times a week (Anderson et al. 2014). Moreover, anthropogenic vectors can frequently travel long-distances $(260-9500 \mathrm{~km})$ between sites and across geopolitical borders (Anderson et al. 2014; De Ventura et al 2016). Accordingly, rapid long-distance dispersal of IAS may occur. For example, when transported overland, $67 \%$ of all moored boats, are subsequently relaunched within less than two days (De Ventura et al 2016).

Conditions other than temperature and humidity regimes, such as the circulation of air currents (i.e. wind speed) can greatly increase desiccation rates resulting in a substantial reduction in fragmentary propagule survival (Bickel 2015). Previously, L. minuta exposed to $58 \%$ RH under stagnant air conditions $\left(21-23{ }^{\circ} \mathrm{C}\right)$ retained viability for up to $4 \mathrm{~h}$ (Coughlan et al. $2015 \mathrm{~b}$ ), however, the current study suggest that viability beyond $4 \mathrm{~h}$ is possible. Despite this, biomass production was less than that observed by Coughlan et al. (2015b), including control sample growth. Stagnant versus circulated air experimental conditions may have influenced biomass production, as circulated air would prevent moist microclimatic shells to persist around damp Lemna colonies (Coughlan et al. 2015a), thus decreasing subsequent viability. Accordingly, fragmentary propagules exposed to increased air currents during transport will likely display reduced survival and viability, dependent on exposure time.

\section{Receiving environments and success of dispersal}

After dispersal has occurred, conditions aside from desiccation exposure and initial propagule biomass, will also affect survival and viability. Species characteristics and many environmental variables, such as sediment nutrients, plant densities, and light intensity, will all affect macrophyte fragment survival and viability (Hoffmann et al. 2015; Kuntz et al. 2014; Li et al. 2015). For example, Hoffmann et al. 
(2015) observed a decrease in the percentage mortality of E. nuttallii fragments with the addition of sediment during establishment trials. However, given that both zoochorous (Coughlan et al. 2017a) and anthropogenic vectors (Anderson et al. 2014) can frequently and rapidly move between freshwater sites, detachment of propagule stages may occur in a suitable receiving environment that is within the invaders ecological amplitude. Moreover, vectors such as waterbirds will regularly and purposefully remove foreign material from their plumage throughout the day, including while sitting upon the surface of waterbodies. Therefore, detachment occurring at a site favourable to establishment is highly possible.

\section{Biosecurity implications}

This study cannot predict the likelihood of establishment by dispersed aquatic macrophyte fragmentary propagules. Nevertheless, data presented here highlight the ability invasive fragmentary propagules to survive and retain viability post desiccation exposure, with some cases of viability after $6 \mathrm{~h}$ desiccation at relatively warm ambient temperatures $\left(\geq 20^{\circ} \mathrm{C}\right)$. Moreover, it is reasonable to assume that larger fragments, damp clumps, propagules with apical tips, would retain a greater capacity for survival and subsequent viability. Thus, biosecurity protocols utilising desiccation strategies to mitigate against invader spread, should consider prolonged desiccation $(>6 \mathrm{~h})$ at high temperatures and low RH (i.e. at high VPD), and even substantially longer desiccation times for inverse conditions as minimum requirements. In practice, however, desiccation as a biosecurity tool alone is likely inadequate to prevent the spread of invasive macrophyte fragmentary propagule stages, as even small desiccated fragments that appear to be dry may still be viable. As compliance with biosecurity practices can be low (Anderson et al. 2014), with stakeholders experiencing a lack of clear guidance (Sutcliffe et al. 2018), increased emphasis should be allocated to inspection and removal of adhering materials. However, good practice protocols such as 'Check, Clean, Dry' should continue to promote extended drying times after initial systematic examination and decontamination has occurred. 


\section{Acknowledgments}

We especially thank Darren Reidy for advice on experimental design, and for the collection, propogation and provision of biological material. We also gratefully thank Dr Simona Paolacci, Mairead Kiely and Don Kelleher for their helpful contributions. Equally, we thank two anonymous reviewers for helpful comments.

\section{References}

Anderson, L.G., White, P.C.L., Stebbing, P.D., Stentiford, G.D., Dunn, A.M., 2014. Biosecurity and vector behaviour: evaluating the potential threat posed by anglers and canoeists as pathways for the spread of invasive non-native species and pathogens. PLoS ONE 9, e92788. doi:10.1371/journal.pone.0092788

Bakker, E.S., Wood, K.A., Pagès, J.F., Veen, G.F.C., Christianen, M.J.A., Santamaría, L. Nolet, B.A., Hilt, S., 2016. Herbivory on freshwater and marine macrophytes: a review and perspective Aquatic Botany 135, 18-36.

Banha, F., Anastácio, P.M., 2015. Live bait capture and crayfish trapping as potential vectors for freshwater invasive fauna. Limnologica - Ecology and Management of Inland Waters 51, 63-69.

Banha, F., Diniz, A., Anastácio, P.M., 2016. The role of anglers' perceptions and habits in biological invasions: perspectives from the Iberian Peninsula. Aquatic Conservation: Marine and Freshwater Ecosystems 27, 51-64.

Barnes, M.A., Jerde, C.L., Keller, D., Chadderton, W.L., Howeth, J.G., Lodge, D.M., 2013. Viability of aquatic plant fragments following desiccation. Invasive Plant Science and Management 6, 320325.

Barrat-Segretain, M.-H., Cellot, B., 2007. Response of invasive macrophyte species to drawdown: the case of Elodea sp. Aquatic Botany 87, 255-261. 
Bengtsson, D., Avril, A., Gunnarsson, G., Elmberg, J., Söderquist, P., Norevik, G., Tolf, C., Safi, K., Fiedler, W., Wikelski, M., Olsen, B., Waldenström, J., 2014. Movements, home-range size and habitat selection of mallards during autumn migration. PLOS ONE 9, e100764. doi:10.1371/journal.pone.0100764

Bickel, T.O., 2015. A boat hitchhiker's guide to survival: Cabomba caroliniana desiccation resistance and survival ability. Hydrobiologia 746, 123-134.

Brain, R.A., Solomon, K.R., 2007. A protocol for conducting 7-day daily renewal tests with Lemna gibba. Nature Protocols, 2, $979-987$.

Bruckerhoff, L., Havel, J., Knight, S., 2015. Survival of invasive aquatic plants after air exposure and implications for dispersal by recreational boats. Hydrobiologia 746, 113-121.

Caffrey, J., Dick, J., Lucy, F., Davis, E., Niven, A., Coughlan, N., 2016. First record of the Asian clam Corbicula fluminea (Müller, 1774) (Bivalvia, Cyrenidae) in Northern Ireland. BioInvasions Records 5, 239-244.

Coughlan, N.E., Kelly, T.C., Davenport, J., Jansen, M.A.K., 2015a. Humid microclimates within the plumage of mallard ducks (Anas platyrhynchos) can potentially facilitate long distance dispersal of propagules. Acta Oecologica 65-66, 17-23.

Coughlan, N.E., Kelly, T.C., Jansen, M.A.K., 2015b. Mallard duck (Anas platyrhynchos)-mediated dispersal of Lemnaceae: a contributing factor in the spread of invasive Lemna minuta? Plant Biology 17 (Suppl. 1), 108-114.

Coughlan, N.E., Kelly, T.C., Davenport, J., Jansen, M.A.K., 2017a. Up, up and away: bird-mediated ectozoochorous dispersal between aquatic environments. Freshwater Biology 62, 631-648.

Coughlan, N.E., Kelly, T.C., Jansen, M.A.K., 2017b. "Step by step": high frequency short-distance epizoochorous dispersal of aquatic macrophytes. Biological Invasions 19, 625-634.

Coughlan, N.E., Stevens, A.L., Kelly, T.C., Dick, J.T.A., Jansen, M.A.K., 2017c. Zoochorous dispersal of freshwater bivalves: an overlooked vector in biological invasions? Knowledge and Management of Aquatic Ecosystems 418, 42. doi: 10.1051/kmae $/ 2017037$ 
Coughlan, N.E., Walsh, D.A., Caffrey, J., Davis, E., Lucy, F.E., Cuthbert, R.N., Dick, J.T.A., 2018. Cold as Ice: a novel eradication and control method for invasive Asian clam, Corbicula fluminea, using pelleted dry ice. Management of Biological Invasions. In Press.

Cuthbert R.N., Coughlan N.E., Crane K., Caffrey J.M., MacIsaac H.J., Dick JTA (2018) A dip or a dab: assessing the efficacy of Virasure ${ }^{\circledR}$ Aquatic disinfectant to reduce secondary spread of the invasive curly waterweed Lagarosiphon major. Management of Biological Invasions. In Press.

De Meester, L., Gòmez, A., Okamura, B., Schwenk, K., 2002. The Monopolization Hypothesis and the dispersal-gene flow paradox in aquatic organisms. Acta Oecologica 23, 121-135.

De Ventura, L., Weissert, N., Tobias, R., Kopp, K., Jokela, J., 2016. Overland transport of recreational boats as a spreading vector of zebra mussel Dreissena polymorpha. Biological Invasions 18, $1451-1466$.

Dudgeon, D., Arthington, A.H., Gessner, M.O., Kawabata, Z.-I., Knowler, D.J., Lévêque, C., Naiman, R.J., Prieur-Richard, A-H., Soto, D., Stiassny, M.L.J., Sullivan, C.A., 2006. Freshwater biodiversity: importance, threats, status and conservation challenges. Biological Reviews 81,163182.

Evans, C.A., Kelting, D.L., Forrest, K.M., Steblen, L.E., 2011. Fragment viability and root formation in Eurasian watermilfoil after desiccation. Journal of Aquatic Plant Management 49, 57-62.

Green, A.J., 2016. The importance of waterbirds as an overlooked pathway of invasion for alien species. Diversity and Distributions 22, 239-247.

Havel, J.E., Kovalenko, K.E., Thomaz, S.M., Amalfitano, S., Kats, L.B., 2015. Aquatic invasive species: challenges for the future. Hydrobiologia 750, 147-170.

Heidbüchel, P., Kuntz, K., Hussner, A., 2016. Alien aquatic plants do not have higher fragmentation rates than native species-a field study from the River Erft. Aquatic Sciences 78:767-777. 
Hoffmann, M., Reader, U., Melezer, A., 2015. Influence of environmental conditions on the regenerative capacity and the survivability of Elodea nuttallii fragments. Journal of Limnology $74,12-20$.

Hussner, A., 2012. Alien aquatic plants in European countries. Weed Research 52, 397-406.

Hussner, A., Stiers, I., Verhofstad, M.J.J.M., Bakker, E.S., Grutters, B.M.C., Haury, J., van Valkenburg, J.L.C.H., Brundu, G., Newman, J., Clayton, J.S., Anderson, L.W.J., Hofstra, D., 2017. Management and control methods of invasive alien aquatic plants: a review. Aquatic Botany $136,112-137$.

Jerde, C.L., Barnes, M.A., DeBuysser, E.K., Noveroske, A., Chadderton, W.L., Lodge, D.M., 2012. Eurasian watermilfoil fitness loss and invasion potential following desiccation during simulated overland transport. Aquatic Invasions 7, 135-142.

Johnson, L.E, Ricciardi, A., Carlton, J.T., 2001. Overland dispersal of aquatic invasive species: A risk assessment of transient recreational boating. Ecological Applications 11, 1789-1799.

Kuehne, L.M., Olden, J.D., Rubenson, E.S., 2016. Multi-trophic impacts of an invasive aquatic plant. Freshwater Biology 61, 1846-1861.

Kuntz, K., Heidbüchel, P., Hussner, A., 2014. Effects of water nutrients on regeneration capacity of submerged aquatic plant fragments. Annales de Limnologie 50,155-162.

Lahive, E., O'Halloran, J., Jansen, M.A.K., 2011. Differential sensitivity of four Lemnaceae species to zinc sulphate. Environmental and Experimental Botany 71, 25-33.

Li, F., Zhu, L., Xie, Y., Jiang, L., Chen, X., Deng, Z., Pan, B., 2015. Colonization by fragments of the submerged macrophyte Myriophyllum spicatum under different sediment type and density conditions. Scientific Reports 5, 11821. doi: 10.1038/srep11821.

Lu, J., Bunn, S.E., Burford, M.A., 2018. Nutrient release and uptake by littoral macrophytes during water level fluctuations. Science of the Total Environment 622-623, 29-40. 
Mommer, L., Visser, E.J.W., 2005. Underwater photosynthesis in flooded terrestrial plants: A matter of leaf plasticity. Annals of Botany 96, 581-589.

O’Hare, M.T., Aguiar, F.C., Asaeda, T., Bakker, E.S., Chambers, P.A., Clayton, J.S., Elger, A., Ferreira, T.M., Gross, E.M., Gunn, I.D.M., Gurnell, A.M., Hellsten, S., Hofstra, D.E., Li, W., Mohr, S., Puijalon, S., Szoszkiewicz, K., Willby, N.J., Wood, K.A., 2018. Plants in aquatic ecosystems: current trends and future directions. Hydrobiologia 153, 1-11.

Piria, M., Copp, G.H., Dick, J.T.A., Duplić, A., Groom, Q., Jelić, D., Lucy, F.E., Roy, H.E., Sarat, E., Simonović, P., Tomljanović, T., Tricarico, E., Weinlander, M., Adámek, Z., Bedolfe, S., Coughlan, N.E., Davis, E., Dobrzycka-Krahel, A., Grgić, Z., Kırankaya, Ş.G., Ekmekçi, F.G., Lajtner, J., Lukas, J.A.Y., Koutsikos, N., Mennen, G.J., Mitić, B., Pastorino, P., Ruokonen, T.J., Skóra, M.E., Smith, E.R.C., Šprem, N., Tarkan, A.S., Treer, T., Vardakas, L., Vehanen, T., Vilizzi, L., Zanella, D., Caffrey, J.M., 2017. Tackling invasive alien species in Europe II: threats and opportunities until 2020. Management of Biological Invasions 8, 273-286.

R Core Team, 2018. R: A Language and Environment for Statistical Computing. R Foundation for Statistical Computing, Vienna.

Redekop, P., Hofstra, D., Hussner, A., 2016. Elodea canadensis shows a higher dispersal capacity via fragmentation than Egeria densa and Lagarosiphon major. Aquatic Botany 130, 45-49.

Riis, T., Madsen, T.V., Sennels, R.S.H., 2009. Regeneration, colonisation and growth rates of allofragments in four common stream plants. Aquatic Botany 90, 209-212.

Rothlisberger, J.D., Chadderton, W.L., McNulty, J., Lodge, D.M., 2010. Aquatic invasive species transport via trailered boats: what is being moved, who is moving it, and what can be done. Fisheries 35, 121-132.

Sala, O.E., Chapin III, F.S., Armesto, J.J., Berlow, E., Bloomfield, J., Dirzo, R., Huber-Sanwald, E., Huenneke, L.F., Jackson, R.B., Kinzig, A., 2000. Global biodiversity scenarios for the year 2100. Science 287, 1770-1774.

Santamaría, L., 2002. Why are most aquatic plants widely distributed? Dispersal, clonal growth and small-scale heterogeneity in a stressful environment. Acta Oecologica 23, 137-154. 
Schultz, R., Dibble, E., 2012. Effects of invasive macrophytes on freshwater fish and macroinvertebrate communities: the role of invasive plant traits. Hydrobiologia 684, 1-14.

Simberloff, D., Martin, J., Genovesi, P., Maris, V., Wardle, D.A., Aronson, J., Courchamp, F., Galil, B., García-Berthou, E., Pascal, M., 2013. Impacts of biological invasions: what's what and the way forward. Trends in Ecology \& Evolution 28, 58-66.

Sutcliffe, C., Quinn, C.H., Shannon, C., Glover, A., Dunn, A.M., 2018. Exploring the attitudes to and uptake of biosecurity practices for invasive non-native species: views amongst stakeholder organisations working in UK natural environments. Biological Invasions 20, 399-411.

Umetsu, C.A., Evangelista, H.B.A., Thomaz, S.M., 2012. The colonization, regeneration, and growth rates of macrophytes from fragments: a comparison between exotic and native submerged aquatic species. Aquatic Ecology 46, 443-449.

Figure 1. Biomass generation (mean $\pm \mathrm{SE}$ ) by Azolla filiculoides and Lemna minuta (both $n=9$ ), 10 and 7 days, respectively, post desiccation at selected temperatures and relative humidity (RH) combinations (see Table 1). All control samples were directly transferred between magenta vessels, without exposure to drought. 
Figure 2. Formation of new shoot biomass (mean $\pm \mathrm{SE}$ ) by Elodea canadensis, E. nuttallii and Lagarosiphon major non-apical stem fragmentary propagules (all $n=18$ ) 28 days post desiccation, and following exposure to selected temperature and relative humidity $(\mathrm{RH})$ combinations (see Table 1). Desiccation regimes of $18 \% \mathrm{RH}$ for all species, and $38 \% \mathrm{RH}$ for E. canadensis, omitted as no new shoot growth was observed. All control samples were directly transferred between magenta vessels, without exposure to drought. 
Table 1: Experimental exposure of aquatic macrophyte propagule stages to desiccation regimes of selected temperature and relative humidity combinations. Calculated specific humidity (SH) and vapour-pressure deficit (VPD) are given.

\begin{tabular}{|c|c|c|c|c|c|c|c|c|c|c|}
\hline \multirow{2}{*}{$\begin{array}{c}\text { Temperature } \\
{ }^{\circ} \mathrm{C} \\
( \pm \mathrm{SE})\end{array}$} & \multirow{2}{*}{$\begin{array}{c}\text { Relative } \\
\text { humidity } \\
\% \mathrm{RH}\end{array}$} & \multirow{2}{*}{$\begin{array}{c}\text { Mean \% RH } \\
\text { achieved } \\
( \pm \mathrm{SE})\end{array}$} & \multirow{2}{*}{$\begin{array}{l}\text { Specific } \\
\text { humidity } \\
\mathrm{g} \mathrm{kg}^{-1}\end{array}$} & \multirow{2}{*}{$\begin{array}{l}\text { Vapour- } \\
\text { pressure deficit } \\
\mathrm{kPa}\end{array}$} & \multicolumn{6}{|c|}{ Exposure time $\mathrm{hr}$} \\
\hline & & & & & 1 & 2 & 3 & 4 & 5 & 6 \\
\hline $20( \pm 0.002)$ & 18 & $18.5( \pm 0.01)$ & 2.59 & 1.92 & All spp. & All spp. & -- & -- & -- & -- \\
\hline $20( \pm 0.002)$ & 38 & $37.9( \pm 0.01)$ & 5.47 & 1.45 & All spp. & All spp. & -- & -- & -- & -- \\
\hline $20( \pm 0.002)$ & 60 & $59.9( \pm 0.01)$ & 8.65 & 0.94 & All spp. & All spp. & All spp. & All spp. & L. minuta & L. minuta \\
\hline $20( \pm 0.002)$ & 85 & $85.1( \pm 0.01)$ & 12.28 & 0.35 & All spp. & All spp. & All spp. & All spp. & L. minuta & L. minuta \\
\hline $27( \pm 0.002)$ & 18 & $18.5( \pm 0.01)$ & 3.95 & 2.93 & All spp. & All spp. & -- & -- & -- & -- \\
\hline $27( \pm 0.002)$ & 38 & $37.9( \pm 0.01)$ & 8.36 & 2.21 & All spp. & All spp. & A. filiculoides & -- & -- & -- \\
\hline $27( \pm 0.002)$ & 60 & $59.9( \pm 0.01)$ & 13.23 & 1.43 & All spp. & All spp. & All spp. & All spp. & L. minuta & L. minuta \\
\hline $27( \pm 0.002)$ & 85 & $85.1( \pm 0.01)$ & 18.81 & 0.54 & All spp. & All spp. & All spp. & All spp. & L. minuta & L. minuta \\
\hline $36( \pm 0.002)$ & 18 & $18.5( \pm 0.01)$ & 6.59 & 4.88 & All spp. & All spp. & -- & -- & -- & -- \\
\hline $36( \pm 0.002)$ & 38 & $37.9( \pm 0.01)$ & 13.98 & 3.69 & All spp. & All spp. & A. filiculoides & -- & -- & -- \\
\hline $36( \pm 0.002)$ & 60 & $59.9( \pm 0.01)$ & 22.18 & 2.38 & All spp. & All spp. & All spp. & All spp. & L. minuta & L. minuta \\
\hline $36( \pm 0.002)$ & 85 & -- & 31.60 & 0.892 & -- & -- & -- & -- & -- & -- \\
\hline
\end{tabular}


Figure 1:

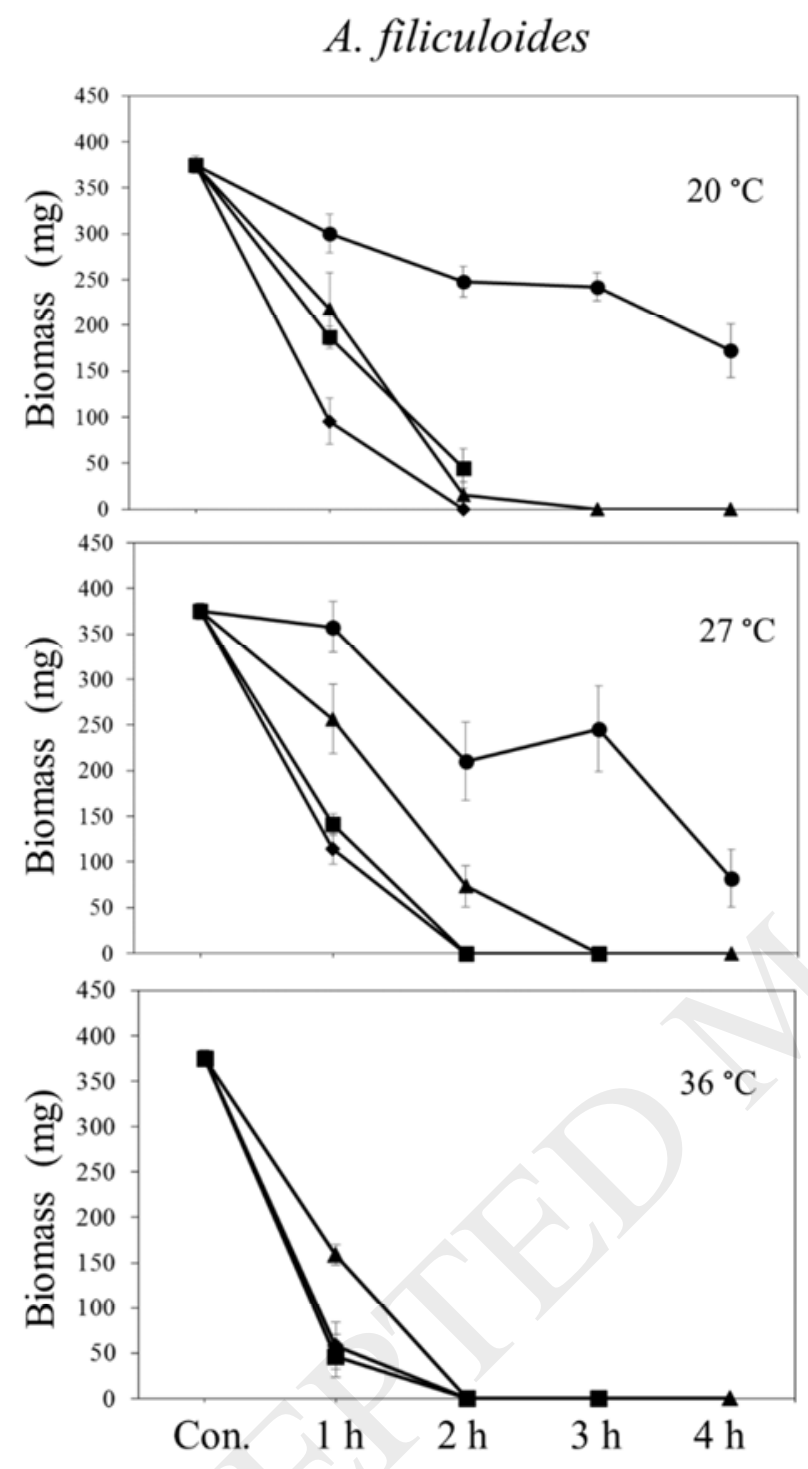

Exposure Time
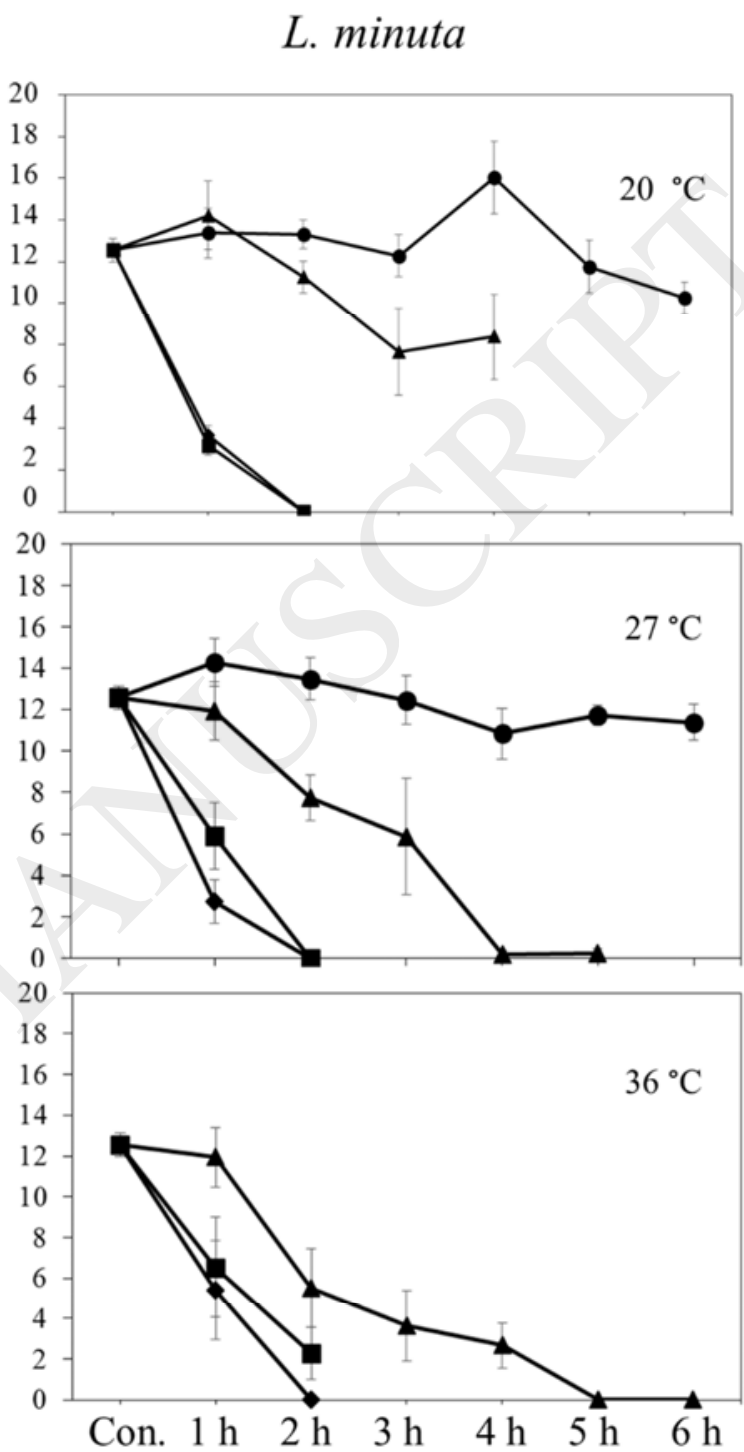

Exposure Time 
Figure 2:
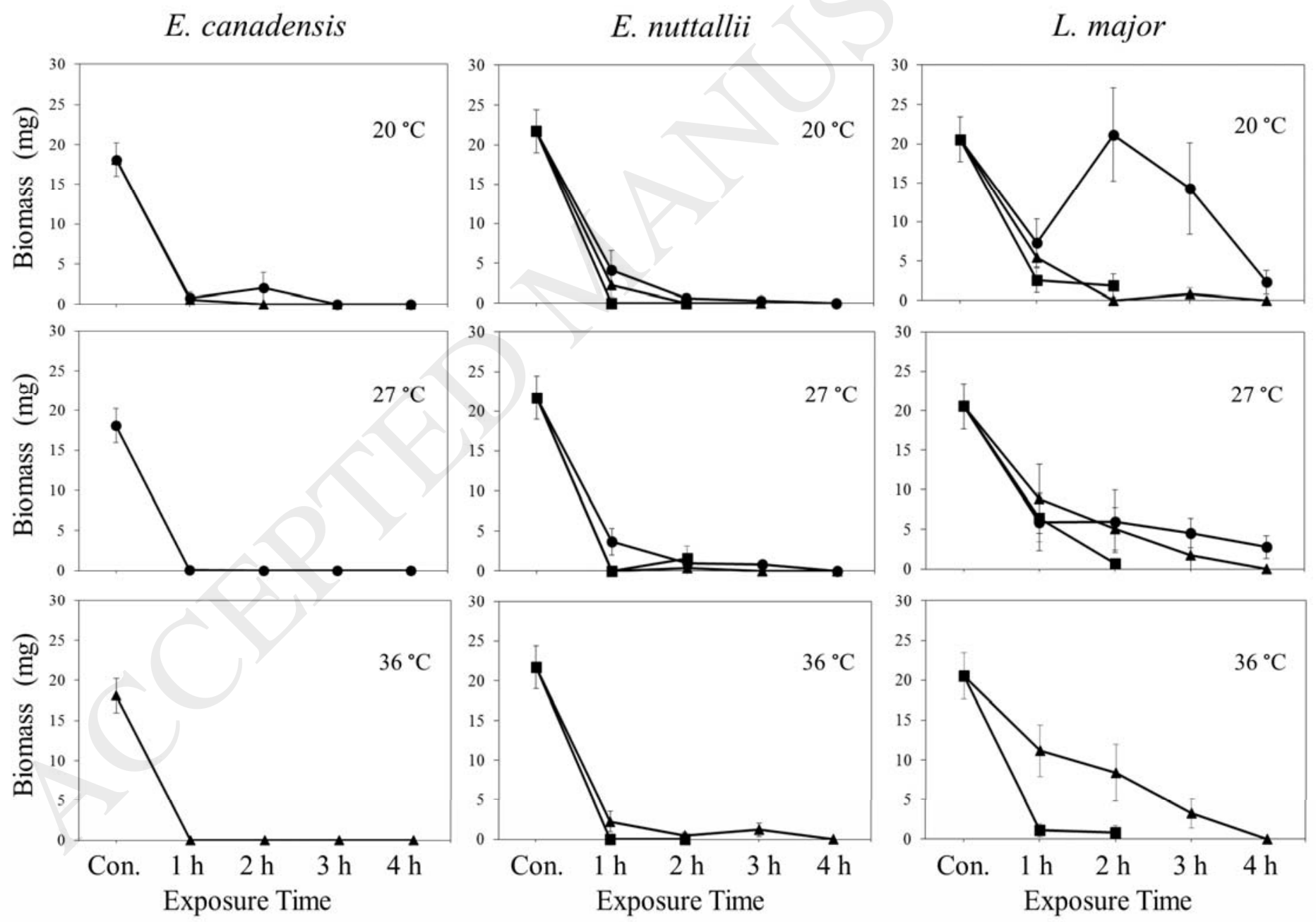

$38 \% \mathrm{RH}$

А $60 \% \mathrm{RH}$

- $85 \% \mathrm{RH}$ 